\title{
What Do You Do When the Unthinkable Happens?
}

\author{
Jeanine Ward-Roof and Joy Smith
}

The intent in writing this article is to offer some thoughts on how to handle a significant crisis prior to and during Orientation. As we discuss this situation, it is important to note that Clemson University administration, faculty, staff, and students all send their condolences to the student's family as they continue to deal with the tragedy that we will discuss.

The sleepy little Southeastern towns of Clemson and Central, South Carolina were riveted during what was supposed to be a restful holiday weekend in May 2006. A student was found dead in her off-campus apartment, and at first, no one was sure what had occurred. As the case unfolded, it was discovered that the student was murdered by an unknown person. Early summer session classes had started and Orientation was less than 3 weeks away. The campus community was under the microscope as the media descended upon the community; the suspect was still at large and seemingly few leads were available in the case. Crisis management meetings occurred with staff from the police department and other municipal services areas, housing, media, dean of students, undergraduate studies, admissions, orientation, and many others. After an in-depth discussion, the following actions were taken:

1. Staff members assisted the student's family and friends during this tragedy to ensure they were able to cope the best they could with the events as they unfolded. This included assisting with the release and relocating of the student's belongings, cleaning out the apartment, and helping friends learn about and cope with the situation.

2. The university widely communicated the events, so people could gather more information, and offered safety tips. Audiences for these communications included students enrolled in summer school, those who had been enrolled in the spring semester, Parents' Council members, all incoming undergraduate and graduate students, the entire campus, and local communities.

3. A Web page was created on the university home page that was continually updated so that community members and others could have a single source for the most current information. This was important as many people began to speculate and many rumors were created.

4. All questions were directed to media relations staff who would refer media to the appropriate people for more information.

5. Police presence was increased in more visible locations on campus.

6. Each new student (undergraduate and graduate) received a letter and e-mail (if we had an e-mail address), informing them of the events, where to find more information, and safety tips.

At the time of submission, Jeanine Ward-Roof (jwardroof@admin.fsu.edu) was the Director of Student Development Services at Clemson University. She is now the Dean of Students at Florida State University. Joy Smith (joy@clemson.edu) is the Associate Vice President of Student Affairs and Dean of Students at Clemson University. 
7. In the opening session for each New Student Orientation, students and parents were informed about the incident and given safety tips and the Campus Safety Report.

8. Other programs that were already in existence or in the process of being created were enhanced, and people were directed to attend them during the orientation program. (The Police Department created a "Safety in the Community" program and the orientation staff created a "One Clemson: A Community of Respect" program for inclusion in the summer program.)

9. Student Government made plans to offer rape aggression workshops in conjunction with the Police Department and the Recreation Center.

Focusing on Orientation, we made the strategic decision to talk about this tragic event and offer facts about the case to all incoming students and answer questions as we were able during each session. Our hope was that we would be able to heal together and make good decisions about our safety if we communicated about the event, did not attempt to hide anything we knew as fact, encouraged everyone to think about safety, and openly shared how we were coping as a community.

By the end of the summer, the perpetrator was apprehended, but the focus on open communication, safety, and security continues. Ideally, other campus communities will not have to deal with a crisis such as this, but if they do, we suggest an open and honest approach as the best way to handle the situation.

Comments on this article may be directed to the authors at jwardroof@admin.fsu.edu or joy@clemson.edu and/or to the editor at drode@niu.edu. "Perspectives" articles represent the opinions and experiences of the author(s) and do not necessarily represent the viewpoints of the JCOT editors. 